\title{
Cultural factor in quality management of Polish enterprises
}

\author{
Zbigniew Klos
}

\section{Abstract}

Since the beginning of nineties Poland and other central European countries have undergone significant economical transformation. It needs the enormous work to be done, using the best methods and ways available. As such also the introduction of the "new culture" into organisations is regarded. Paper deals with the role of the enterprise culture in quality management in Poland. At the beginning, after some historical and actual remarks concerning economy, the meaning of the enterprise culture is defined as well as its symptoms are presented. Then the main elements of shaping enterprise culture in Polish enterprises are described. The conditions of culture introduction to these organisations are reviewed in two spheres: external and internal. National features of Poles in implementation of culture into enterprises are also considered and its role is shown. Examples of original enterprise culture are presented and shortly the Polish Quality Award is characterized.

\section{Short historical perspective}

At the beginning of new century, some Polish quality experts state that an introduction of the Total Quality Management (TQM) is one of the last chances for the Polish economy to revitalize it. It is obvious in the situation of the entry of Poland into global market now and joining the European Union soon. Our country and neighbour countries have lately undergone transformation, but the necessity of adaptable works which still should be done is evident. The best methods in this field are originated from TQM and culture area. They could be applied at the different levels of economy, being specially suitable in the corporations (organisations). Poland laid on the one of main routes of mediaeval Europe - the Amber Transit Route - from Baltic to Mediterranean countries. From that time, first made by Polish craftsmen wares began to circulate along the Europe. The evidence that they were good-quality products was the creation of permanent market-places and the organisation of fairs. The example of such a activity were to see for instance in towns like Poznan and Cracow.

Serious check of Polish goods took place in the second part of XIX century when invaders tried to limit our economy. For this purpose they established financially supported organisations. But after the long battle carried out in Province of Great Poland and called ,the longest war of modern Europe”, the thousands of craftsman's workshops and farms remained in Polish hands, thanks to the higher quality of produced there goods and the better quality of work.
We could be proud by the reason of input of Professor Florian Znaniecki to the foundations of the science of quality, specially to what is now called as TQM. His concept on enterprises as the dynamic technical systems, published before II World War, preceded the current proposals by tens of years.

\section{Market economy in Poland}

The main goal of organizations in market economy is to serve customers, in a broader sense - to fulfil market needs. According to the opinion of F. Moskal, Director of Can-Pol Chamber of Commerce, as well as vice-president of Canadian Poles Congress, the situation in last years has changed significantly in Poland. Specially it is seen in the field of commerce, which is now practically almost $100 \%$ privately owned.

The second element of market economy - the assurance of possibility to choose products and services - has important influence on fulfilment of the first demand. F.Moskal sees in this field a great progress in Poland, specially on the market of consumer goods and services, although the possibility of choosing them are still not so broad as in the developed countries.

The next element, necessary to right functioning of market economy, is the assurance of the condition for honest competition for all organizations on the market, national and foreign. This competition forces the organizations to the development of such a processes which transform the material, energetic and human stocks in market products with higher market value. Here also F.Moskal has observed the real progress, specially in the area of consumer goods and services, where stateowned organizations left rather behind in the competition.

As a last considered here element of market economy, the reaching of sufficient profitability is mentioned, to use profits partly for re-investment and partly for improve of living standard of personnel. In comparison to developed countries where this first option is mainly chosen, in Poland the living standard of majority of population is still distinctly lower than in Western Europe and the pressure is observed to devote more from the profit for increasing salaries.

As one can see, the basis for the market economy has been already developed in Poland and it gives good prognosis for introduction of corporate culture and TQM. How TQM is understood here, it is shown in later. 


\section{Enterprise culture}

The term "culture" is known from ages, but the term "enterprise (or corporate or organisation) culture" is more commonly known only from about thirty years. It is defined that the corporate culture is the pattern of declared convictions and values, which give the corporate co-workers the sense of activities and rules of behaviour [1].

As a culture symptoms:

- the criteria of promoting to higher ranks,

- the criteria of recitation,

- the way of contacts with customers,

- the layout and the way of creation of organisation documentary,

- the architecture and the state of organisation infrastructure,

- the readiness of co-workers to work in overtime,

- the way of communication in organization, are amongst other seen.

\section{Review of culture introduction factors}

All factors which are connected with culture introduction to Polish corporations can be gathered in two groups:

1) external, dependent on factors from the environment of corporate,

2) internal, typically inside corporate dependent.

\subsection{External factors}

Speaking about the external factors influencing the introduction of culture to Polish enterprises one can remember about two aspects:

a) historical conditions, which shape the situation in Poland not only in economy, but also in social area,

b) actual conditions.

All facts which have influenced on the attitude towards work, its quality and the quality of products had historical conditions. Some of them have been mentioned earlier in this paper.

Among the actual conditions one can distinguish:

- economical,

- social.

As a actual condition of key importance for successful introduction of culture strategy to Polish organisations, the reconstruction of the whole national economy for the quality-oriented goals is mentioned. S. Sudol presenting the results of the inquiry shows, that the factors which are friendly to reaching these goals, the experts arranged in following order [2]:

a) socially accepted, concise pro-quality concept of economy,

b) complete turnover from centrally-steered to marketcontrolled economy,

c) significant increase of foreign investments,

d) consequence in introduction of market-controlled economy,

e) demonopolization of production,

f) remarkable structural changes in Polish economy.
As we see, the demand of acceptance and introduction of pro-quality concept of economy $(a, d, f)$ is more important then the changes of management mechanisms (b, e) and inflow of foreign capital (c).

The privatisation of corporate is seen as a main factor to obtain high quality products. As an important element, the positive changes in attitude to work amongst the staff, specially top management, have been found by B. Nogalski in many analysed organisations [3].

Speaking about the social conditions one can mentioned the specific national features of Poles, which belong also to the external, from the point of view of position to organisation, conditions. They are, as follows:

- skill of achieving the goals in unconventional ways,

- unrecognition of authorities,

- aspiration to freedom,

- need of quick personal success.

Poles are seen world-wide as an individualists with high ambitions, open-minded, flexible, talented improvisers, innovative and fast learning. When one combine these features with the Polish predilection to improve everything around and the great criticism, this mixture is seen by E. Kindlarski to be promising starting point for attaining quality goals [4].

To the social conditions, the region differentiation in Poland also belongs. The GNP per capita is already two and half times higher in the best regions then in the worst [5]. According to the report from the Institute of Studies on Market Economy, the Wielkopolska region is one of three the best in Poland. In all specified below categories: consumption, workforce, industrial infrastructure, transformation of economy and environment for business this region is in highest class of an attractiveness. It is the generally held opinion of inhabitants from other parts of Poland that inhabitants of Wielkopolska characterise themselves by particularly careful and conspicuous attitude to work. It is obviously very important in a period of creating a new economic order and it results in dynamic economic transformation in the region and in the material well-being of its inhabitants. At the foundations of this fact, the high quality of work, products and services lies.

\subsection{Internal factors}

To create starting point to analyse the conditions of TQM introduction into Polish organisations, the author of this paper has prepared own complex definition of TQM [6] (figure 1).

The elements mentioned in TQM definition are treated here as a basis for analysis of internal conditions of culture introduction into Polish organisations.

System approach is the activity, which uses the ordered set of mutually interrelated elements of given entirety for its maximum effectiveness. In Japan this entirety is formed by organisation with the all elements of its environment (so called community of interest): top management and staff of organisation, bank, customers and suppliers. The purpose of the 


\title{
T $\quad \mathrm{Q} \quad \mathrm{M}$
}

\section{IS THE WAY OF ORGANISATION MANAGEMENT}

characterised by:

\author{
\# system approach \\ \# orientation on strategic goals \\ \# ability to continuous and for ever improvement \\ \# active team activity of whole staff,
}

with full engagement of top management

\section{WHICH LEADS TO FULFIL THE NEEDS OF CUSTOMERS IN GIVEN MOMENT AND IN FUTURE WITH THE MINIMUM COSTS}

done by use of people and applied by them quantitative methods to:

- assessment and rationalisation of all important processes in the organisation,

- improvement of delivery (materials and services) supplied to the organisation

\section{AND WHICH IS CULTURAL CHANGE OF MANAGEMENT STYLE OF ORGANISATION}

Figure 1: Definition of TQM

creation of such an entirety is the long-term profit for all interested parties of given community. Defined in this way system approach does not exist in and around the majority of Polish organisations. Individual examples are the exceptions. It is rather seen opposite tendency in organisations to confine their frames to minimum dimensions. Besides the positive "surgeon" role of cutting superfluous units, this process brings the threat of liquidation of departments which are extemporary non-profit, but needed for long-term operation of organisation, for example R\&D departments.

Dealing with the strategic goals, in survey done by B. Nogalski $3 / 4$ of organisations declared that they had their own strategy, but over $70 \%$ of them had only shortterm ones [3]. Thanks to the TQM, the goals of the organisations are maximised and the specific consonance and stability of goals are created. As it is seen in Poland, there are only few results of such an activity. The goals of organisations rarely go down to departments and to the single staff member.

When considering ability for continuous and for ever improvement, it is well known that introducing TQM into organisation, new philosophy of systematic process improvement of its functioning ought to be build-in, instead of situation of fighting fires or quick fixes. It is obvious, that it is much easier to do it in stable surroundings of constant rules of market. Considering still changeable principles of operation on the Polish market, only few organisations have the good possibilities in respect with it.

Active team engagement of full staff to work on improvement of quality is probably the greatest challenge in the whole chain of activities in introduction of TQM to organisations. The conscience of the importance of quality factor for organisation market success is still limited, specially amongst workers. Top management is deeply influenced by some factors, also the threat of job loss. It has been stated that in Poland two times more persons from top management reach the satisfaction from their work then workers. Some differences are noticed in dependence of regional location of organisations. Dissemination of the TQM idea is still often done by enthusiasts.

As mentioned earlier the fulfilment of customer needs should be reached with minimal costs. The production processes are still often organised in the way to minimise first of all the costs. The quality level is only the derivative of this fact. Changes connected with privatisation increase the range of the application of economical tools of management, mainly for minimisation of costs.

Use of quantitative method and people to rationalisation of all important processes in organisation is various. In many of them the application of quality assurance tools stopped at the level of SPC. The importance of described here aspect is visible, when one consider the hierarchy of sources of work effectiveness. The need of processes rationalisation is here on the first position.

Cultural change is not often meet in many organisations because the culture, as a system of common values and goals, is mainly the stable element of organisations. In many corporates the endeavour to reach first of all the quantitative goals, specially financial, is very strong. Improvements, which are not leading to above mentioned goals, are not popular. As an element of desired culture change, the need of continuous rationalisation of organisation structure is seen. This idea, specially for staff of state-owned organisations, is still often new. 


\section{Some results of TQM introduction into corporate}

"To endow the people in such a way that one can select the best from the best, to produce using best ingredients and to do not look round that the competitors have lower prices. To go forward only aiming at the highest quality, with the prices fully justified by delicious taste and elegant packing of chocolates". There were words of Dr. Jan Wedel, owner in 1919-1939 of the famous Warsaw factory of chocolates "E. Wedel". Starting in 1919, after the death of his father Edward, with some tens of workers, he attained in 1939 the personnel of 1350 workers and the opinion of the best chocolate and chocolate confectionary producer in Poland.

After the study at the university in Fryburg (Switzerland), where he had obtained Ph.D. in chemistry, he further completed his knowledge at the Mechanical Engineering Faculty at Technical University Berlin-Charlottenburg and went through the practical training in confectioneries and chocolate factories in Britain, France, Germany and Switzerland.

The specific approach of J. Wedel to quality problems has been described by J. Zandberg. Let us see how, according to the some items from up-to-date requirements, some 65 years ago Dr. Wedel fulfilled demands of quality standards [6].

In area of management tasks we can treat the declaration quoted at the beginning of this chapter as his commitment to quality policy. J. Wedel spent daily in his office only one hour. Rest of his working day he was inspecting the process of chocolate production, starting from raw material and ending at the finished product, so the review of quality system done by the representative of senior management can also be accepted.

For the production of the cream chocolate candies such a best ingredients were used as old cognacs and wines, the most aromatic fruits and the best sorts of chocolate. Just before II World War, first steps towards buying the plantation of cocoa grain was done for the assurance of the stable quality of this raw material. Quality of milk was very carefully checked and most of it came from the farms located in Poland's submountain region. Suppliers, whose products were two time called in question, were unappealable dismissed from the suppliers list.

The firm had the chain of own shops round the Poland. Own trucks fleet, as well as chartered trucks and even one plain assured that the products reached the shops very quickly and in unchanged state.

The packages of products, designed by artists, were often formed in series, as "Fairy-tales", "Cars", "Plains" or "Movies", where photos of film stars were attached. They were not only beautiful but also very well protecting the products against the quality changes. Together with the very high quality of product, they caused that in 1934, during 11-months lasting the round-theglobe trip of Polish sailing-boat "Dar Pomorza", tested chocolate did not change their taste and look.

Treatment of non-conforming to quality standard pro- ducts were very formalised. Found from time to time faults were corrected by withdrawing the lots of products, even when prepared to expedition. The passion of J. Wedel was to keep of hygienic rules. Any deviations in this matter were not tolerated.

This was the history of Wedel factory and how it is now? Is it TQM known in Poland? Or may be we should first ask about knowledge and acceptance of general market economy rules, which make the roots of TQM?

It is also interesting to look at the advantages of TQM introduction from the point of view of one organisation, the producer of components to electrical machines and appliances. E. Skrzypek described the long lasting battle of this enterprise for the ISO 9000 certificate [7]. Direct impulse for starting the attempts towards improving quality system was the real threat of price reduction of the products, signalised by foreign contractors. After two and half year, the quality system was accepted by English notified body.

The positive results for external situation of corporate after the rewarding the certificate are listed below:

- better image of enterprise on the Polish and global market,

- maintaining of the prices of the products at the same level,

- better starting point for contracts negotiations.

In organisation, the following positive effects are noticed:

- common understanding that the improvisation is not the right approach to reach quality goals,

- precisely defined rights and duties on the every workplace,

- possibility of revealing of all faults, errors and mistakes by effective identification of their reasons,

- recurrence of the behaviour in every case thanks to the procedures,

- increasing responsibility for quality through the personnel,

- respect for the order and precision in ever activity,

- decrease of defective products, reaching according to value $50-60 \%$.

\section{Polish Quality Award}

To reward the best Polish organisation, introducing TQM principles, Polish Quality Award (PQA) was recently established. The first edition of the competition was carried out in 1995. The reward was awarded for organisation "... which through the introduction of TQM has gained the increase of the satisfaction of customers, its own staff and other enterprises connected with organisation (e.g. suppliers) and reached in this way the significant improvement of work, processes, quality system and also achieved market success".

The first prize-winner of this competition was ZELMER, leading in Poland $(90 \%$ of market in vacuum cleaners, 60-70\% - in food mixers and $70 \%$ - in expresses) and in Europe (ranked as a second in vacuum cleaners) producer of household equipment. The sale and profitability of sale have continuously increased in ZELMER in last years and is now above $12 \%$. 


\section{Conclusions}

Poland is seen as a country with a one of the fastest growing economy in Europe. The GNP, started in 1992 with 2,6 \% increase - reached in $19956,5 \%$ of annual increase. Above $60 \%$ of employees are working now in private sector.

These and other parameters are basis for prognosis that Poland will be among the first Central and East European countries, which will join European Union economical structures. Now it takes still some $2-3$ years, but taking into consideration the historical perspective, we are close to this moment.

Having in mind this situation, Polish organisations should and I hope that they will work with increasing force on improving their quality systems. Also official confirmation of quality system existence, by appreciating for certificate, will be of interest for hundreds and then thousands of organisations. Number of several hundreds of ISO 9000 certificates, obtained in last 5 years, will increase now in more faster rate.

It is to observe among the organisations, which are ISO 9000 certificate holders for some years, that they try to reach now higher level of excellence in quality area by introducing TQM and shaping their own individual corporate culture. I hope that this sound tendency will be kept in future.

\section{References}

[1] Davies, S. M.; Managing corporate culture. Harper \& Row Publ. New York 1985

[2] Sudol, S.; Pro-quality policy. Przeglad Organizacji, 1992, no 2 (in Polish)

[3] Nogalski, B.; Privatisation - symptoms of changes. Przeglad Organizacji, 1993, no 3 (in Polish)

[4] Kindlarski, E.; Polish Quality Way. Proceedings of the 36th Quality Congress, Brussels 1992

[5] Domagala, J.; Regions for Europe. Zycie Gospodarcze, 1996, nr 41 (in Polish)

[6] Klos, Z.; Introduction of TQM strategy to Polish enterprises - analysis of conditions. Organizacja i Kierowanie, 1996, no 1 (in Polish)

[7] Skrzypek, E.; The way of KFK to the ISO certificate. Problemy Jakosci, 1994, no 3 (in Polish)

\section{Author}

Ass. Prof. Dr. habil. (Eng.) Zbigniew Klos

Poznan University of Technology

Institute of Machines and Motor Vehicles

ul. Piotrowo 3, 60-965 Poznan, Poland

Tel. +48616652231

Fax +48616652736

E-Mail: zbigniew.klos@put.poznan.pl 